\title{
Deprem Etkisindeki Yapıların Sismik Taban İzolasyonu ve Çoklu Ayarlı Kütle Sönümleyici Sistemleri ile Karma Korunması
}

\author{
Sepanta NAIMI* (D), Mohammad Harris WAHEB \\ İstanbul Aydın Üniversitesi, İnşaat Mühendisliği, İstanbul \\ Geliş / Received: 07/02/2019, Kabul / Accepted: 08/03/2019
}

\begin{abstract}
Öz
Deprem öngörülemez ve önlenemez bir gerçektir, can ve mal kaybını en aza indirgemek için tek çaba, yapıyı depreme bağlı kuvvetlere karşı koyacak şekilde tasarlanması ve inşa edilmesidir. Özellikle Kobi, Northridge ve Düzce depremleri gözönünde bulundurulduğunda hastane, okul gibi kamu binalarının ve çok-katlı binaların depreme karşı temel izolatörlerle korunması gerekliliği öngörülmektedir. Yapılar için istenen depreme dayanıklı bir tasarıma ulaşmak için çeşitli girișimlerde bulunulmuștur. Bu girișimler sonucunda, bir deprem sırasında yapısal tepkileri azaltmak için önemli ölçüde faydalı olan önemli ilerlemeler kaydedilmiştir. Farklı deprem yer hareketleri altında tek ayarlı kütle sönümleyici (STMD), çoklu ayarlı kütle sönümleyicileri (MTMD'ler) ve dağıtılmış çoklu ayarlı kütle sönümleyicileri (d-MTMD’ler) kullanılarak, taban izolasyonlu yapıların sismik tepki kontrolünün incelenmesi gerekmektedir. Bu çalışmada yapı, tabakalı kauçuk mesnetler (LRB), kurşun çekirdekli kauçuk mesnetler (N-Z), sürtünmeli sarkaç sistemi (FPS) ve esnek sürtünmeli taban izolatörü (RFBI) izolasyon sistemleri ile izole edilmiş ve en üst katta STMD, MTMD'ler ve tabanda MTMD'ler ve katlarda d-MTMD'ler ile donatılmıştır. Ayrıca parametrik çalışma için izolatör zaman periyodu 2 ile 2,5 ve 3 sn arasında değiştirilerek gerçekleştirilmiștir. Tüm STMD durumları için kütle oranı \%2, 3, 5 ve \%10 olarak kabul edilmiştir. Buna ek olarak, MTMD’ler en üst katın yanı sıra taban üzerine yerleştirilmiş ve izole edilmiş yapının yüksekliği boyunca dağıtılmıştır.
\end{abstract}

Anahtar Kelimeler: Sismik Taban-İzolatörü, Sönümleme, Ayarlı Kütle Sönümleyici, Sürtünme, Depreme Dayanıklı Yapılar, Betonarme Yapılar.

\section{Hybrid Protection of Earthquake Excited Structures by Using Seismic Base Isolation and Multiple Tuned Mass Damper Systems}

\begin{abstract}
Earthquake is an unpredictable and inevitable fact, and the only effort to minimize the loss of life and property is to design and build the structure to resist the forces associated with earthquakes. Considering the Kobi, Northridge and Düzce earthquakes in particular, it is foreseen that public buildings such as hospitals, schools and multi-storey buildings should be protected with basic isolators against earthquakes. Various attempts have been made to achieve an earthquake-resistant design desired for buildings. As a result of these initiatives, significant progress has been made, which is significantly beneficial to reduce structural responses during an earthquake. The seismic response control of base insulated structures must be examined using single-set mass damper (STMD), multiple-set mass dampers (MTMDs) and distributed multiple-set mass dampers (d-MTMDs) under different earthquake ground motions. In this study, the structure was isolated with stratified rubber supports (LRB), lead-core rubber bearings (NZ), friction pendulum system (FPS) and flexible friction base insulator (R-FBI) isolation systems and on the top floor STMD, MTMDs and MTMDs at floors and d-MTMDs on floors. Also, for the parametric study, the insulator time period has been realized by changing between 2 and 2.5 and $3 \mathrm{sec}$. The mass ratio for all STMD cases was accepted as 2, 3, 5 and 10\%. In addition, MTMDs were placed along the top floor as well as on the base and distributed throughout the height of the isolated structure.
\end{abstract}

Keywords: Seismic Base-Isolator, Damping, Tuned Mass Damper, Friction, Earthquake Resistant Building, Reinforced Concrete Buildings.

\section{Giriş}

Yeryüzünün ani ve geçici hareketi deprem olarak adlandırılmaktadır. $\mathrm{Bu}$ hareket, yer kabuğundaki enerji tahliyesi, kabuğun yerinden çıkması, volkanik patlama, yeraltı boşluklarının çökmesi, bombalar, hatta insan yapımı patlamalar gibi farklı kaynaklardan meydana gelebilmektedir. Depremler, can ve mal kaybına neden olabilecek, doğanın 
ortaya çıkardığı en yıkıcı güçlerden biridir. Yapıların yer değiştirme ve ivme tepkilerini kontrol etmek için çok sayıda titreşim kontrol sistemlerinin çeşitleri geliştirilmiştir. Günümüzde, dünya çapında, bu titreşim kontrol sistemleri, inşaat mühendisliği alanında yaygın olarak kullanılmaktadır ve yapıların tepkisini kontrol etmede etkili olmuştur.

Az ve orta katlı bir yapıda, gerekli esneklik sadece temel düzeyde taban izolasyonu kullanılarak elde edilebilir. Taban izolasyonu, yapının tabanında daha fazla esneklik sağlar, izolasyon sistemi, depremin yer değiştirme talebini toplu olarak absorbe eder ve üst yapı rijit bir gövde olarak yer değiştirir. Ayrıca, taban-izolasyon sistemleri kendisi de nispeten büyük bir yer değiştirmeye maruz kalır. Taban-izolasyon sisteminin tasarımında önemli bir nokta, yer değiştirme talebidir. Taban-izolasyonlu yapıların yer değiştirme talebini azaltmak için TMD'ler kurulmaktadır. TMD, yapının tek bir temel frekansina optimal olarak ayarlanabileceğinden, sistem, bir frekans oranı için en etkili olanı olabilir. Ayrıca kütle oranı da önemli bir faktör olacaktır ve sönümleme de önemli bir rol oynar. TMD'nin dezavantajlarından, TMD'lerin frekansının yapının kontrollü frekansına ayarlanmasinda dalgalanma nedeniyle duyarlılık problemi olduğu bulunmuştur. Yanlış ayarlama veya optimum olmayan sönümleme TMD'nin etkililiğini önemli ölçüde azaltır. MTMD'lerin, eşit kütle ve sönümleme oranına sahip bir STMD'den daha etkili olduğu analizlerde gösterilmiştir. d-MTMD'lerin modal özelliklere uygun olarak kurulumu, STMD'den ve en üst kattaki tüm TMD'lerden daha etkili olduğu kabul edilmektedir. Ayrıca, taban-izolasyonu ve TMD-birleşik stratejisi, rezonans frekanslarına yakın güçlü bir enerji muhtevasına sahip olan sismik uyarımın azaltılmasında etkili olarak düşünülebilir. TMD ile donatılmış taban izolasyonlu yapıların tepkisi, giriş deprem yer hareketine oldukça bağlıdır. TMD'nin yapıya eklenmesi, giriş frekansı yapının doğal frekansından daha düşük olduğunda yapı tepkisini artırmaktadır. MTMD'ler ile tabanizolasyonlu yapının tepkisi, MTMD'ler olmadan ki tepkisiyle karşılaştırıldığında daha azdır, bu da MTMD'lerin tabanizolasyonlu yapının kuvvetlerini ve yer değiştirmelerini azaltmada etkili olduğunu göstermektedir. $\mathrm{Bu}$ çalışmada, gerçek deprem yer hareketleri altında tek ayarlı kütle sönümleyici (STMD), çoklu ayarlı kütle sönümleyicileri (MTMD’ler) ve dağıtılmış çoklu ayarlı kütle sönümleyicileri (dMTMD'ler) ile donatılmış taban izolasyonlu (BI) yapının sismik tepkileri incelenmiştir. Sayısal çalışma, STMD, MTMD'ler ve dMTMD'ler ile donatılmış 5,10 ve 15 katlı taban izolasyonlu yapıların analitik modelleri kullanılarak gerçekleştirilmiştir. Yapı, her kat seviyesinde yatay tek serbestlik derecesine sahip kesme-tipi yapı olarak modellenmiştir ve yapı, tabakalı kauçuk mesnetler (LRB), kurşun çekirdekli kauçuk mesnetler (N-Z), sürtünmeli sarkaç sistemi (FPS) ve esnek sürtünmeli taban izolatörü (R-FBI) izolasyon sistemleri ile izole edilmiştir. Taban izolasyonlu bir yapının her bir kat seviyesinde bir TMD kurmak, en üst kat ivmeleri ve mesnet yer değiştirmeleri açısından yapısal tepkiyi azaltmaktadır. Parametrik çalışmalar için iki set MTMD ((i) eşit rijitliğe ve eşit sönümleme oranına sahip MTMD’ler) ve (ii) eşit kütleye ve eşit sönümleme oranına sahip MTMD'ler) düşünülmüştür. Deprem, rüzgâr ve ağır makine yüklerine maruz kalan yapılar, yapıya zarar verebilecek veya muhtemelen çökebilecek titreşimlere maruz kalabilmektedirler. Yapılara bağlı titreşimi azaltmak ve yapısal güvenliği ve dayanıklılığg geliştirmek için, son yıllarda çeşitli titreşim kontrol sistemleri geliştirilmiştir. Titreşim kontrol sistemleri, enerji dağıtıcı nitelikleriyle ön plandadır. $\mathrm{Bu}$ 
yapısal kontrol sistemleri pasif, aktif, yar1aktif ve karma olarak sınıflandırılmaktadır.

\subsection{Pasif Kontrol Sistemleri}

Pasif kontrol cihazları, yapının hareketini kullanarak cihazın bulunduğu yerlerde kuvvetler geliştirir. Geliştirilen kuvvetlerin nedeniyle, bazı giriş enerjilerini absorbe ederek yapıdaki enerji yayılım talebini azaltır ve yapısal sisteme enerji katamaz. Ayrica, pasif kontrol cihazlarının sistemini aktifleştirmek için herhangi bir aktüatöre ihtiyacı yoktur. Ayarlı kütle sönümleyici, ayarlı sıvı sönümleyici, metalik akma sönümleyici, viskoz akışkan sönümleyici ve kurgu sönümleyici pasif kontrol cihazlarının örnekleridir.

\subsubsection{Taban-İolasyon Sistemleri}

Taban-izolasyon, pasif kontrol yaklaşımlarından biridir. Kauçuk gibi düşük yanal rijitliğe sahip bir malzemeye monte edilen bir yap1 esnek bir taban oluşturur. Temel fikir, üstyapının yapının tabanından ayrılmasıdır. Ankastre mesnetli yapısının temel zaman periyodunu daha büyük bir değere kaydırır. Yapısında, malzemenin yanal yönde esnek malzeme kullanılarak zaman periyodunun artırılmasi, yapının sismik enerjiyi dağıtmasına ve sismik kuvvetlere direnmesine olanak sağlar. Tabanizolasyon, alçak ve orta yükseklik yapıların korunmasında etkilidir. Esnek taban, yüksek frekansları yer hareketinden filtrelediğinden ve bu tip yapıların yüksek frekanslı olmasıyla karakterize edilir.

Naimi ve Kamiarfar (2016) faya yakın güçlendirilmiş yapıların üzerinde depremin etkisini incelemişlerdir; depremin etkisiyle iki komşu yapıda çarpışma meydana gelmesi sonucunda binada hasar oluşmuştur. Bu tarz hasarları önlemek için farklı yönetmeliklere göre güçlendirmenin 3 yönteminden birisi olarak 'damperler (sönümleyiciler) ve izolatörlerin kullanılmasından bahsetmişlerdir, ayrıca tüm yapılarda yer değiştirme değerleri fay hattından uzak depremden elde edilen kayıtları yönetmelikte belirlenen maksimum miktardan az olduğunu, yer değiştirme değerleri fay hattına yakın ivme kayıtları etkisi altında, yönetmelikte belirlenen maksimum miktardan daha fazla olduğunu, yapılarda temel kesme kuvveti fay hattından uzak olan ivme kayıtlarında, faya yakın olana göre daha az olduğunu ve yapı güçlendirmeleri yapısal rijitlik yükselişiyle temel kesme kuvveti yükselmesine neden olduğunu bulmuşlardır. Özkaya vd. (2011), bilyeli kauçuk mesnedi (BRB) adı verilen yeni bir kauçuk tabanlı sismik izolatör geliştirmeyi amaçlayan deneysel araştırmanın sonucunda çelik bilyelerin sadece elastomerik mesnetlerin enerji yayılımını arttırmakla kalmayıp, aynı zamanda yatay ve düşey rijitliğinin de arttırdıklarını bulmuşlardır, (Özkaya vd., 2011; Naimi ve Kamiarfar, 2016).

İzolatörler genellikle iki ana tipten (i) elastomerik, (ii) Sürgülü-tip mesnetlerden birinde sinıflandırılmaktadır. Elastomerik mesnetler tipik olarak, montaj ünitelerinin sürtünme işlemi yapılmış yüzeyleri ile karakterize edilen Sürgülü-tip mesnetlerin bulunduğu kauçuk ve çelik plakalardan oluşmaktadır. Elastomerik mesnetler, yatay rijitlik ve sönümleme kapasitesine kıyasla yüksek dikey rijitlik ve sönüme sahiptirler. Sürgülü sistemler, sürtünme katsayısı ve mesnetlere uygulanan dikey kuvvetler tarafindan uygulanan yanal kuvvetlere direnmektedir. Taban-izolasyon sistemleri aşağıdaki çeşitlere kategorize edilebilir:

a) Tabakalı kauçuk mesnetler (LRB)

b) Kurşun çekirdekli kauçuk mesnetler veya $\mathrm{N}-\mathrm{Z}$ sistemi

c) Sürtünmeli sarkaç sistemi (FPS)

d) Saf sürtünmeli sistemi (PF)

e) Esnek-sürtünmeli taban-izolasyon sistemi (R-FBI) 
f) Fransiz elektrik sistemi (EDF)

LRB, N-Z ve FPS İzolasyon Sistemleri için sırasıyla Şekil 1'e bakınız.

\subsection{Aktif Kontrol Sistemleri}

Bu tip kontrol cihazları, yapıya kontrol gücü sağlayan aktüatörleri çalıştırmak için önemli miktarda güç gerektirmektedir. Aktif kontrol stratejisi, uygun kontrol gücünü belirlemek için tüm yapı üzerindeki tepkiyi ölçüp tahmin edebilmektedir. Aktif ayarlı kütle sönümleyici, aktif ayarlı sıv1 kolon sönümleyici ve aktif değişken rijitlik sönümleyici, aktif kontrol cihazlarının örneklerindendir.

\subsection{Yart-Aktif Kontrol Sistemleri}

Yarı aktif kontrol cihazları, hem pasif hem de aktif cihazların olumlu yönleridir. $\mathrm{Bu}$ cihazlar, yapısal sisteme enerji ekleyemeyen yapının hareketi sonucunda kuvvet üretir. Yarı-aktif kontrol cihazlarının çalışması için küçük bir harici güç kaynağı gereklidir. Değişken orifis sönümleyici, değişken sürtünmeli sönümleyici, değişken rijitlik sönümleyici ve kontrol edilebilen ayarlı sıv1 sönümleyici, yarı-aktif kontrol cihazlarının örnekleri olarak adlandırılabilir.

\subsection{Karma Kontrol Sistemleri}

$\mathrm{Bu}$ kontrol cihazları tipik olarak pasif ve aktif veya yar1-aktif cihazları bir kombinasyonundan oluşur. Karma kontrol cihazları, her sistem tek başına hareket ettiğinde mevcut kisitlamaların ve kısıtlamaların bir kısmını hafifletebilir. $\mathrm{Bu}$ nedenle, karma kontrol sistemini kullanan daha yüksek performans seviyeleri elde edilebilir. Kontrol hedefinin bir kısmı pasif kontrol sistemi ile gerçekleştirilir, bu nedenle daha az aktif kontrol çabasına ihtiyaç vardır ve daha az güç kaynağına ihtiyaç duyulduğunu gösterir. Ayrıca, elektrik kesintisi durumunda, pasif kontrolün bileşenleri, tamamen aktif kontrol sistemlerinden farklı olarak hala bir dereceye kadar koruma sağlar. Karma kütle sönümleyici ve karma taban-izolasyonu, karma kontrol sisteminin örneklerindendir.

\subsection{Ayarlı Kütle Sönümleyici (TMD)}

Ayarlı kütle sönümleyicileri, en eski yapısal titreşim kontrol cihazların arasındadır. Titreşim kontrol kavramı bir kütle sönümleyiciyi kullanarak Frahm'ın icat ettiği 'dinamik titreşim sönümleyici' adlı titreşim kontrolü 1909 yılına dayanır (Frahm, 1909). TMD bir kütle, bir yay ve bir sönümleyiciden oluşur, deprem ve rüzgâr yükleri nedeniyle üretilen binaların tepkilerini kontrol etmek için genellikle binaların en üst katlarına yerleştirilen pasif bir cihazdır.

Ayrıca, TMD'ler rüzgâr kaynaklı titreşimi kontrol etmek için esnek köprü ve kulelere yerleştirilir. Bir TMD, bir sönümleyici sistemiyle bir yapıya bağlı bir kütleden oluşur, $180^{\circ}$ faz kayması ile ana yapı ile aynı frekansta titreşir ve kütle ile yapı arasında geliştirilen ilişkin hareketle enerjiyi dağıtır. TMD'lerin en önemli özelliği, TMD'nin frekansını yapının temel doğal frekansına eşitleyen frekansların ayarlanmasıdır. Sönümleyicinin doğal frekansı, ana sistemin doğal frekansına yakın bir frekansa ayarlanmakta, ana sistemin titreşimi, sönümleyicinin rezonansta titreşmesine neden olmakta, ayarlı kütle sönümleyicinde sönümleme yoluyla titreşim enerjisini dağıtmaktadır. Tek ayarlı kütle sönümleyicinin dezavantajlarından biri, yapının doğal frekansındaki ve/veya ayarlı kütle sönümleyicinin sönümlenme oranındaki hataya olan duyarlılığıdır. Sızma ya da boşta kalma, bir TMD'nin etkililiğini önemli ölçüde azaltır. Birincil sistemdeki veya TMD’lerdeki belirsizliklerin sağlamlığını arttırmak için, farklı dinamik özelliklere sahip birden fazla TMD kullanımı önerilmiştir. Iwanami ve Seto (1984), iki ayarlı TMD'nin tek bir TMD'den daha etkili olduğunu göstermiştir. Bununla birlikte, 
verimliliği pek belirgin değildi. Xu ve Igusa (1992, 1994), dağıtılmış doğal frekansları olan çoklu ayarlı kütle sönümleyicileri önermişler ve en uygun şekilde tasarlanmış MTMD'lerin en uygun şekilde tasarlanmış tek bir TMD'den daha etkili ve dayanıklı olduğunu göstermişlerdir. Bekdaş ve Niğdeli (2011) ve Niğdeli (2013) Ayarlı kütle sönümleyicinin optimum parametresini araştırmışlardır; bugün dünyada kullanılan çoğu TMD'lar, lineer ve pasiftir (yani, yalnızca yapının hareketine tepki olarak tepki verdikleri ve harici olarak sürülmedikleri anlamına gelir). Pasif lineer TMD'ler pratikte çok etkili ve güvenilirdir (Bekdaş ve Niğdeli, 2011; Bekdaş ve Niğdeli, 2013). Ayarlı kütle sönümleyici (TMD) Şekil 2'te gösterilmiştir.

\section{Materyal ve Metot}

Günümüzün modern dünyasında, inşaat mühendisliği alanında taban-izolasyon ve TMD titreşim kontrol teknikleri başarıyla kullanılmaktadır. Her tekniğin kendine özgü avantajları ve sınırlamaları vardır. Örneğin, belirli bir deprem altındaki taban-izolasyon, kabul edilemez sınırlar içinde büyük bir yer değiştirmeye maruz kalabilmektedir. Deprem süresinin uzunluğu TMD'nin tam işlevselliğe ulaşması için yeterli değilse, yapının tepkisini artırabilir. Avantajları elde etmek ve her iki tekniğin (taban-izolasyonu ve TMD) eksikliğini gidermek için karma pasif kontrol sistemi önerilmektedir. İzolasyon sistemini ayarlı kütle sönümleyici ile birleştiren karma sistemde, üst kat ivme ve mesnet yer değiştirme, ayarlı kütle sönümleyicileri takılarak önemli ölçüde kontrol edilebilmektedir.

\subsection{Karma Sistemi}

Taban izolasyonu, yapının tabanında daha fazla esneklik sağlar; izolasyon, depremin yer değiştirme talebinin bir kısmını söner ve üstyap1 önemli bir şekilde rijit bir gövde olarak yer değiştirir. TMD ve tabanizolasyonun bir kombinasyonu olan bir karma sistem, taban-izolasyonlu yapının ivmelenme tepkisini azaltmadan, izolasyon sistemi tarafından getirilen aşırı yer değiştirmeyi sınırlayabilir. Karma sistem bazı temel dinamik özelliklere sahip olmalıdır. İlk olarak, TMD ve tabanı izole-edilmiş yapı arasında rezonans tepkisini elde etmek için zorunlu olan karma sistemin sönümleyicisinin ayarlanmasi. İkincisi, TMD'nin aktivasyonunun sinırlarını tanımlayan, tabandan izole-edilmiş yapı ile TMD arasındaki duyarlılık ve etkileşim. Üçüncü olarak, üç alt sistemden, yani yapıdan, TMD'den ve izolatörlerden kaynaklanan klasik olmayan sönümleme faktörü. Karma sistemde, kütle oranı ve ayar oranı gibi TMD parametreleri, en iyi performansı sağlamak için özellikle taban izolasyonu yapılan binaya göre ayarlanacaktır.

\section{2. Çalışmanın Amacı}

Çalışmanın birinci amacı, bir TMD'yi kullanarak taban izolasyonlu binadaki aşırı büyük yer değiştirmelerin yanı sıra ivme tepkisini kontrol etmektir.

a. İki boyutlu (2B) beş katlı bir binanın matematiksel modelleme ve analizini yapmak ve elde edilen sonuçların standart sonuçlarla karşılaştırılması (kontrolsüz ve taban izolasyonla kontrollü durumları için).

b. İki boyutlu (2B) beş katlı bir binanın matematiksel modelleme ve analizini yapmak ve elde edilen sonuçların standart sonuçlarla karşılaştırılması (kontrolsüz ve ayarlı kütle sönümleyicileri ile kontrollü durumlar için).

c. En üst katta TMD ile donatılmış taban-izolasyonlu yapının sismik performansını değerlendirmek.

d. En üst katta çoklu ayarlı kütle sönümleyicileri (MTMD'ler) ile donatılmış taban-izolasyonlu yapının sismik performansını değerlendirmek. 
e. Katlarda dağıtılmış çoklu ayarlı kütle sönümleyicileri (d-MTMD'ler) ile donatılmış taban-izolasyonlu yapının sismik performansını değerlendirmek.

f. STMD, MTMD'ler ve d-MTMD'lerle donatılmış taban-izolasyonu binaları üzerinde parametrelerini ve farklı katlarda yerlerini değiştirerek parametrik çalışmalar yapmak.

g. STMD, MTMD'ler ve d-MTMD'ler için sönümleyici ünitelerinin tabanizolasyonlu bir yapı içinde yerleştirilmesi için uygun tavsiyelere ve önerilere varmak.

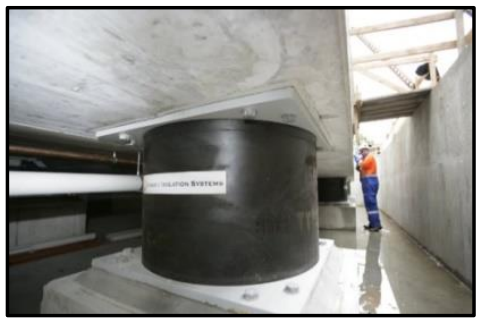

(a)

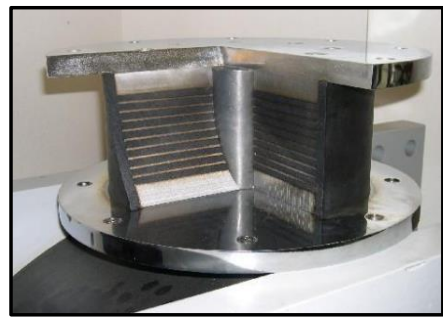

(b)

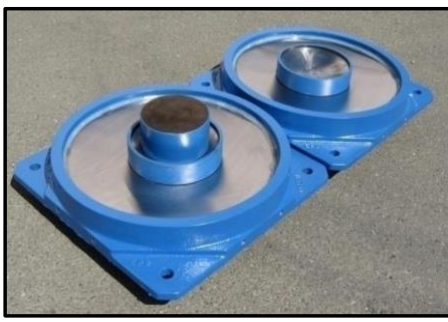

(c)

Şekil 1. (a)Tabakalı Kauçuk Mesnetler (LRB) (b) Kurşun Çekirdekli Kauçuk Mesnetler (N-Z) (c) Kurşun Çekirdekli Kauçuk Mesnetler (N-Z)

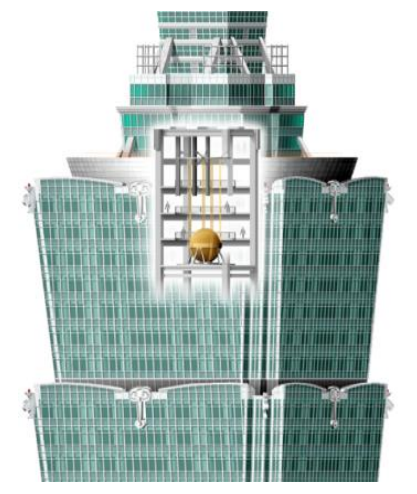

Şekil 2. Ayarlı Kütle Sönümleyici (TMD)

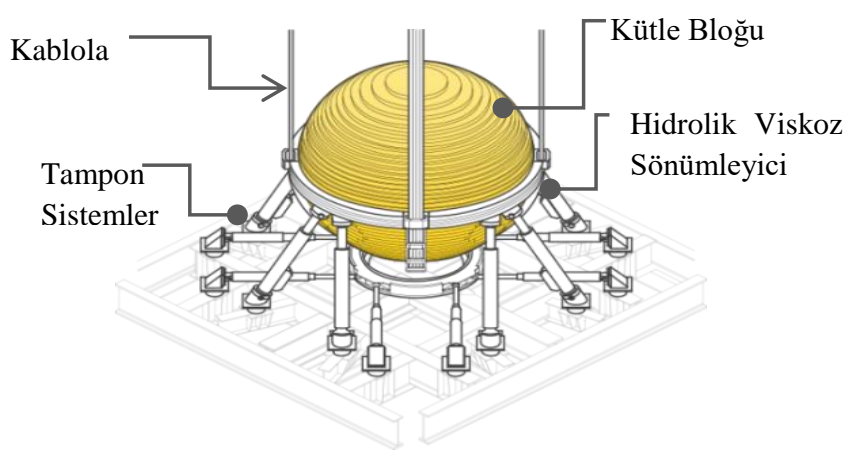

\section{Bulgular ve Tartışma}

\subsection{Genel}

Çoğunlukla deprem bölgesinde yer alan yapılar genellikle depremden etkilenmekte olup, doğal afet sirasında meydana gelen sismik dalgalar nedeniyle yer sarsintısında sismik deformasyona veya yeryüzü tektonik plakalarında bir miktar deformasyona neden olmaktadır.

Sismik dalgalar enerjiyi bir noktadan başka bir noktaya, farklı katmanlardan geçirir ve sonunda enerjiyi yeryüzüne taşır. İletilen enerji bir deprem odak noktasından büyüklük ve mesafeye bağlı yapılara zarar verebilir. Sismik bölgede bulunan yapıların tepkisini en aza indirgemek için, önceki bölümde kısaca tartı̧̧lan çeşitli titreşim kontrol sistemleri geliştirilmiş̧ir.

\subsection{Taban Izolasyonu}

Taban izolasyon sistemi, yapının esas zaman periyodunu, sabit taban yapısının zaman periyodundan daha büyük olacak şekilde daha büyük bir değere değiştirmektedir. Sonradan vibrasyon kontrolü kabul edilmesiyle inşaat mühendisliği problemlerinde yaygın olarak uyguland (Brock, 1946). Kelly (1986), düşükten orta dereceye kadar yükselen binalarda, gerekli esnekliğin ancak temel düzeyde, tabanizolasyon kullanılarak elde edilebileceğini belirtmiştir. Ayrıca, esnek ilk kat kavramını 
önermiştir. Taban-izolasyon sistemleri üzerine yapılan karşılaştırmalı bir çalışmada Su vd. (1990) tasarım koşullarında, tüm izolatörlerin üstyapıya iletilen ivmenin azaltılmasında önemli ölçüde faydalı olduğunu bulmuşlardır. Ayrıca, tabanizolasyonlu yapıların, yapının doğal frekansı ile aynı frekansta yüksek amplitüdlü, yüksek frekanslı salınımın etkisinden korunabileceğini bulmuşlardır, İzolatörleri uygun bir şekilde tasarlayarak, yapıya iletilen tepe yer ivmesini azaltabileceğini ve tepe yer değiştirmesini kontrol edilebilir bir aralıkta tutabileceğini öne sürmüşlerdir. Mokha vd. (1990) taban-izolasyonunda Teflon mesnetlerini incelediğinde, kayma hızlanmasının sürtünme kuvvetlerinin kayıtlı değerleri üzerinde cüzi bir etkiye sahip olduğunu göstermektedir. Ancak kayma hızı ve mesnet basincı önemli ölçüde etkilenecektir. Hız sürtünmesindeki artışın belirli bir miktara kadar artabileceğini ve bu hızın ötesinde sabit kaldığını göstermiştir. Jangid ve Datta (1995) rastgele uyarıma maruz kalan asimetrik yapı için üç tip tabanizolasyon sisteminin (LRB, N-Z ve R-FBI) performansını araştırmışlardır. R-FBI sistemi tarafindan izole edilen asimetrik binanın stokastik tepkisinin parametrik varyasyona daha az duyarlı olduğunu bulmuşlardır. Ayrıca çift yönlü kuvvetlerin üstyapının tepkisini azalttığını ve N-Z mesnetleri durumunda taban yer değiştirmesini artırdıklarını bulmuşlardır (Jangid ve Datta, 1995).

\subsection{Ayarlı Kütle Sönümleyici (TMD)}

Ayarlı kütle sönümleyici, belirli bir frekansta istenmeyen titreşimi azaltmak için titreşimli bir ana sisteme bağlı bir kütle, bir yay ve viskoz sönümleyiciden oluşan klasik bir mühendislik cihazıdır. TMD kavramın kökeni Frahm'ın (1909) bir girişiminden kaynaklanmaktadır. Daha sonra Randall vd. (1981), doğrusal sönümlü birincil sistem için en uygun lineer titreşim sönümleyiciyi incelemiştir. Soong ve Dargush (1997),
TMD'lerin yapının ilk modal katkısıyla kontrol edildiği zaman en etkili olduğunu belirtmiştir. Rana ve Soong (1998) TMD parametrelerinde detunasyonun etkisinin giderek yapısal sönümleme ve / veya kütle oranı ile daha az zararlı olduğunu bildirmişlerdir. Ayrıca, SDOF yapısı ve TMD sistemi üzerine yapılan zaman analizinden, büyük bir yapı sönümlemesi için TMD'nin çok fazla tepki azaltmadığını gözlemlemişlerdir. Üstelik en uygun parametre değerlerinin TMD'nin taban uyarımı veya ana kütle uyarımı için tasarlandığına göre farklılık gösterdiklerini bulmuşlardır (Rana ve Soong, 1998). Li ve Liu (2002), TMD'nin dezavantaj1 olarak, TMD'lerin frekansının, yapının kontrollü frekansina ayarlanmasinda ve / veya TMD'nin sönümleme oranında dalgalanma nedeniyle oluşan duyarlılık sorununu bildirmişlerdir. Daha sonra Krishnamoorthy ve Shetty (2005), yapisal sönümleme, TMD sönümleme, TMD kütle oranı ve uyarım frekansının, tepesinde TMD'ye sahip bir yapının tepkisi üzerinde önemli etkiye sahip olduğunu bulmuştur.

\section{4. Çoklu-Ayarlı Kütle Sönümleyici (MTMD)}

Yapının doğal frekansındaki hataya karş1 duyarlılık veya STMD'nin sönümleme oranı STMD'nin dezavantajlarından biridir. STMD'nin etkililiği, TMD'de yanlış ayarlama veya optimum olmayan sönümleme ile önemli ölçüde azalmaktadır. Iwanami ve Seto (1984, 1985), çift ayarlı kütle sönümleyicilerinin optimum tasarımını incelemiş ve STMD'den daha etkili olduklarını bildirmişlerdir. $\mathrm{Xu}$ ve Igusa (1992) yakın aralıklı frekanslı çoklu altosilatör kullanımını önermişlerdir. Optimal olarak tasarlanmış MTMD'lerin, eşit toplam kütleye ait optimal olarak tasarlanmış bir STMD'den daha etkili ve sağlam olduklarını doğrulamışlardır. Yamaguchi ve Harnpornchai (1993), STMD'ye kiyasla MTMD'lerin performansının arttığını 
bildirmiştir. Abe ve Fujino (1994), MTMD'lerin osilatörlerden en az birinin herhangi bir modda yapıyla güçlü bir şekilde birleştiğinde etkili olduğunu araştırmışlardır. Birincil sistemdeki veya STMD'deki belirsizliklerin sağlamlığını arttırmak için, farklı dinamik özelliklere sahip birden fazla TMD'nin kullanılması Jangid (1995) tarafından önerilmiştir. Kareem ve Kline (1995), frekans periyodunun, toplam sönümleyici sayısının ve sönümleme oranının en uygun şekilde seçilmesiyle optimal bir MTMD sisteminin tasarlanabileceğini belirtmişlerdir, aynı toplam kütle oranı için daha etkili olduğunu bulmuşlardır.

\subsection{Karma Sistemi}

Yukarıda belirtilen tüm yöntemlerin kendi sinırlamaları vardır. $\mathrm{Bu}$ nedenle, karma sistem, taban-izolasyonundan oluşmaktadır. Yang vd. (1991) kauçuk mesnetleri ve pasif ayarlı kütle sönümleyicini birleştiren bir karma kontrol sistemini tanımlamıştır, (Yang et al., 1991). Tsai (1995), TMD ile donatılmış taban-izolasyonlu binalara verilen tepkinin, giriş depreminin yer hareketine oldukça bağlı olduğunu göstermiştir. Ayrıca, TMD'nin yapıya eklenmesinin, giriş frekansı yapının doğal frekansından daha düşük olması durumunda yapisal tepkiyi artıracağını bulmuştur. Ancak, problemin taban izolasyonu için ciddi olmadığının doğru olduğunu belirtmiştir, çünkü tabanizolasyonlu yapıların doğal frekansının genellikle gerçek depremlerin baskın frekansından daha düşüktür. Maksimum tepki, deprem uyarımının erken döneminde gerçekleşir ve hızlandırılmış TMD, izolatörün maksimum deformasyonunu etkili bir şekilde azaltabilmektedir (Tsai, 1995). Palazzo vd. (1997), ayarlı kütle sönümleyicilerle donatılmış taban izolasyon sistemlerinin, rastgele uyarımlara olan tepkisini araştırmışlardır. Tabanın üzerine yerleştirilmiş ek ayarlı kütle sönümleyicinin, izolasyon sisteminin yüksek bir sönümleme değerine sahip olduğu durumlar haricinde, taban-izolasyonlu sistemlerin sismik tepkisini önemli ölçüde azalttığını bulmuşlardır. Ayrıca, ayarlı kütle sönümleyicinin taban izolasyonlu sistemlere uygulanmasinın izolasyon tekniklerinin genişletilmesine izin verdiğini bildirmişlerdir. Kareem (1997), taban-izolasyonlu binaların analizinin klasik sönümleme varsayımıyla yapılabileceğini bulmuştur, ancak bu tür TMD'ler gibi sabit taban ve taban-izolasyonlu yapıları klasik sönümleme varsayımla doğru bir şekilde analiz edilemeyebilir. Palazzo vd. (1999), birleşmiş bir taban-izolasyon ve ayarlı kütle sönümleme stratejisi önermişlerdir. Tabanizolasyonu ile birleştirilmiş ayarlı kütle sönümleyici kullanımının, her zaman izolatörün doğrusal olmayan davranışının varlığında bile genel sistem tepkisinin azalmasını içerdiğini bulmuşlardır. Ayrıca, düşük sönümleme ve ayarlı kütle sönümleyiciyle donatılan taban-izolasyonlu sistemlerin, izolasyonlardaki eşdeğer bir sönümlenme artışıla elde edilen performansa kıyasla daha iyi bir performans sergilediklerini bildirmişlerdir.

\subsection{Matematiksel Modelleme ve Analiz}

\subsubsection{Genel}

$\mathrm{Bu}$ çalışma için çok katlı bina çerçevesi düşünülmektedir. Projenin hedefleri, gerçek deprem yer hareketleri altında ayarlı kütle sönümleyicileri ile donatılmış taban izolasyonlu binaların tepkilerini incelemektir. Üstyapı için toplanmış kütle modellemesi yapılmıştır, izolatör tabanında ve TMD’ler de en üst katın yanı sıra tabanında da yerleştirilmiştir. $\mathrm{Bu}$ çalışmada dönmenin, yap1, izolatör ve TMD üzerindeki etkisi ihmal edilmiştir ve analizler SAP2000 kullanılarak gerçekleştirilmiştir. Ayrıca yapısal sistem için aşağıdaki varsayımlar yapılmıştır:

a. Deprem uyarımı sirasında üstyapının elastik sınırda kaldığı varsayılmaktadır. 
b. Katların kendi düzlemlerinde rijit olduğu varsayılır ve kütle her bir kat seviyesinin iki ucunda toplanır.

c. Kolonlar ve kirişler, yanal rijitlik sağlayan, uzamaz ve ağırlıksızdır.

d. Sistem, deprem yer hareketinin yatay tek yönlü bileşenine maruz kalır ve

e. Zemin yapısı etkileşiminin (SSI) etkisi ihmal edilmektedir.

\subsubsection{Geçerli Olan Hareket Denklemleri}

Sistemimiz için geçerli olan hareket denklemi, her bir serbestlik derecesinin bulunduğu yerde kuvvet dengesi dikkate alınarak elde edilir. $\mathrm{Bu}$ sistem için hareket denklemi şu şekilde ifade edilir:

$[M]\{\ddot{u}(t)\}+[C]\{\dot{u}(t)\}+[K]\{u(t)\}=-[M]\{r\}\left\{\ddot{u}_{g}\right\}$

Burada $[M],[C]$ ve $[K]$, sirasiyla karma sistemle donatılmış binaların kütle, sönümleme ve rijitlik matrisleridir. $\{u\}=\left\{u_{1}, u_{2}, \cdots u_{N}\right\}^{T}, \quad \dot{u}_{\text {ve }} \quad \ddot{u}_{\text {sirasiyla }}$ bilinmeyen ilişkin (yer, izolatör ve TMD) yer değiştirme, hız ve ivme vektörleridir, $\ddot{u}_{g}$ deprem yer ivmesi ve $\{r\}$ etki katsayılarının vektörüdür.

\subsubsection{Ankastre Mesnetli Yapı}

Yatay yer hareketine maruz kalan ankastre mesnetli yapısı için genel hareket denklemi denklem (3.2) olarak yazılabilir. Kütle matrisi $[M]$ ve rijitlik matrisi $[K]$ aşağıdaki gibi yazılabilir:

$[M]=\left[\begin{array}{ccccc}m_{1} & 0 & \cdots & 0 & 0 \\ 0 & m_{2} & \cdots & 0 & 0 \\ \vdots & \vdots & \ddots & \vdots & \vdots \\ 0 & 0 & 0 & m_{N-1} & 0 \\ 0 & 0 & 0 & 0 & m_{N}\end{array}\right]$

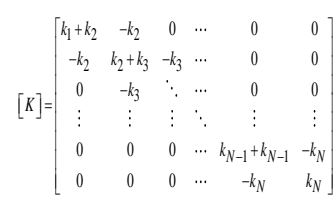

Üstyapının sönümleme matrisi $[C]$ açıkça bilinmemektedir. Sabit tutulan üstyapı için modal sönümleme oranı varsayılarak türetilir.

\subsubsection{Taban-İzolasyonlu Yapı}

Üstyap1-izolatör modeli için genel hareket denklemi (3.1) denklemi olarak ifade edilebilir. Kütle matrisi $[M]$ ve rijitlik matrisi $[K]$ aşağıdaki gibi yazılabilir:
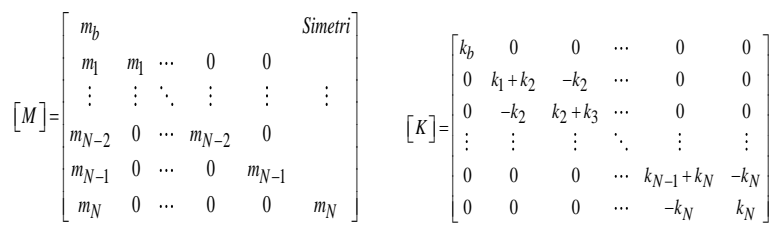

\section{(3.3)}

Üstyapının sönümleme matrisi, $[C]$ açıkça bilinmemektedir. Sabit tutulan üst yapı için modal sönümleme oranı varsayılarak türetilir.

\subsubsection{Ayarlı Kütle Sönümleyici ile Donatılmış Yapı}

En üst katta TMD ile donatılmış ankastre mesnetli N-katlı bina dikkate alınır; TMD kütle $m_{\mathrm{T}}$ değerini varsayarak $c_{\mathrm{T}}$ ve rijitliği $k_{\mathrm{T}}$, hareket denklemi (3.1) denklemi ile aynıdır. Sistemin kütle matrisi aşağıdaki gibi yazılabilir:

$[M]=\left[\begin{array}{cccccc}m_{1} & 0 & \cdots & 0 & 0 & \\ 0 & m_{2} & \cdots & 0 & 0 & \\ \vdots & \vdots & \ddots & \vdots & \vdots & \vdots \\ 0 & 0 & \cdots & m_{N-1} & 0 & \\ 0 & 0 & \cdots & 0 & m_{N} & \\ 0 & 0 & \cdots & 0 & 0 & m_{\mathrm{T}}\end{array}\right]$

En üst katında TMD ile donatılmış yapı için rijitlik matrisi şu şekilde yazılabilir:

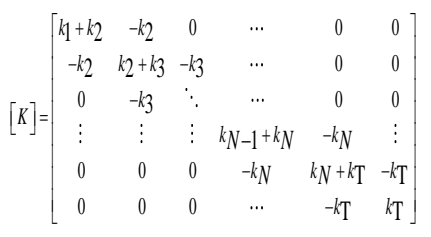




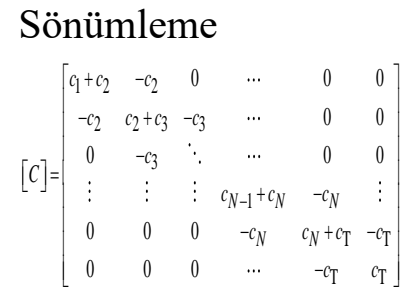

matrisi

(3.2) denklemindeki sönümleme sabiti, keyfidir; $\mathrm{Bu}$ nedenle, sönümleme matrisi genel olarak kütle ve rijitlik matrisi ile orantılı değildir.

\subsubsection{4. Çoklu Ayarlı Kütle Sönümleyicileri ile Donatılmış Yapı}

MTMD'ler ile donatılmış ankastre mesnetli $\mathrm{N}$-katlı bina dikkate alındığında, hareket denklemi denklem (3.1) ile aynıdır. Kütle matrisi $[M]$, rijitlik matrisi $[K]$ ve sönümleme matrisi $[C]$ aşağıdaki gibi yazılabilir:

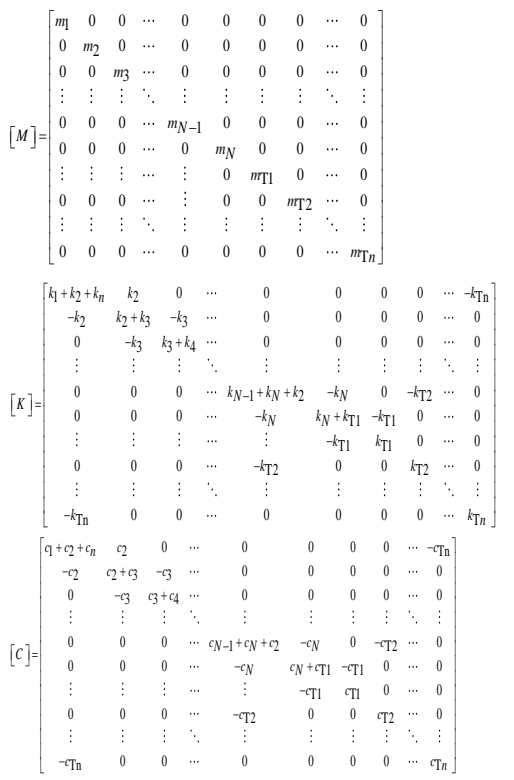

\subsubsection{Karma Önerilen Model}

MTMD'ler ile donatılmış taban-izolasyonlu $\mathrm{N}$-katlı bina dikkate alındığında, hareket denklemi (3.1) denklemi ile aynıdır. Karma sistemle donatılmış binaların kütlesi $[M]$, sönümleme $[C]$ ve rijitlik $[K]$ matrisleri aşağıdaki gibi yazılabilir:

$$
\begin{aligned}
& {[M]=\left[\begin{array}{ccc}
{\left[m_{b}\right]_{1 \times 1}} & & \text { Simetri } \\
{\left[M_{N}\right]_{N \times N}} & {\left[M_{N}\right]_{N \times N}} & \\
{\left[m_{n}\right]_{n \times n}} & 0 & {\left[m_{n}\right]_{n \times n}}
\end{array}\right]} \\
& {[C]=\left[\begin{array}{ccc}
{\left[c_{b}\right]_{1 \times 1}} & & \text { Simetri } \\
0 & {\left[C_{N}\right]_{N \times N}+\left[c_{n}\right]_{N \times N}} & \\
0 & -\left[c_{n}\right]_{n \times n} & {\left[c_{n}\right]_{n \times n}}
\end{array}\right]} \\
& {[K]=\left[\begin{array}{ccc}
{\left[k_{b}\right]_{1 \times 1}} & & \text { Simetri } \\
0 & {\left[K_{N}\right]_{N \times N}+\left[k_{n}\right]_{N \times N}} & \\
0 & -\left[k_{n}\right]_{n \times n} & {\left[k_{n}\right]_{n \times n}}
\end{array}\right]}
\end{aligned}
$$

$\left[m_{b}\right],\left[M_{N}\right]$ ve $\left[m_{\mathrm{n}}\right]$, sirasiyla izolatör, üstyap1 ve TMD şemaları için kütle matrisleridir. İlişkin sönümleme matrisleri ise $\left[c_{b}\right],\left[C_{N}\right]$ ve $\left[i_{n}\right]$ dir. Benzer şekilde, $\left[k_{b}\right],\left[K_{N}\right]$ ve $\left[k_{n}\right]$, sırasıyla izolatör, üstyapı ve TMD şemaları için rijitlik matrisleridir. Matrisler birleştirilmiş sistem için $(N+n+1) \times(N+n+1)$ şeklindedir. TMD'lerin taban seviyesine yerleştirilmesi durumunda, karma sistemle donatılan binaların kütlesi $[M]$, sönümleme $[C]$ ve rijitlik $[K]$ matrisleri aşağıdaki gibi yazılır:

$$
\begin{gathered}
{[M]=\left[\begin{array}{ccc}
{\left[m_{b}\right]_{1 \times 1}} & & \text { Simetri } \\
{\left[m_{n}\right]_{n \times n}} & {\left[m_{n}\right]_{n \times n}} & \\
{\left[M_{N}\right]_{N \times N}} & 0 & {\left[M_{N}\right]_{N \times N}}
\end{array}\right]} \\
{[C]=\left[\begin{array}{ccc}
{\left[c_{b}\right]_{1 \times 1}} & & \text { Simetri } \\
0 & {\left[c_{n}\right]_{n \times n}} & \\
0 & 0 & {\left[C_{N}\right]_{N \times N}}
\end{array}\right]} \\
{[K]=\left[\begin{array}{ccc}
{\left[k_{b}\right]_{1 \times 1}} & & \text { Simetri } \\
0 & {\left[k_{n}\right]_{n \times n}} & \\
0 & 0 & {\left[K_{N}\right]_{N \times N}}
\end{array}\right]}
\end{gathered}
$$

\section{Sayısal Çalışma}

STMD, MTMD'lerin ve d-MTMD'lerin taban izolasyonlu binaların tepki azaltılmasında etkililiği araştırılmıştır. Sayısal çalışma, STMD, MTMD'ler ve dMTMD'ler ile donatılmış taban izolasyonlu binaların analitik modelleri kullanılarak gerçekleştirilmiştir. Bina, her kat seviyesinde yatay tek serbestlik derecesine sahip kesme tipi yapı olarak modellenmiştir. Binanın birleştirilmiş diferansiyel denklemi, Newmark'ın 'adım-adım entegrasyon' yöntemini kullanarak artımlı formda türetilmiş ve çözülmüştür. STMD, MTMD'ler ve d-MTMD'lerle donatılmış 5, 10 ve 15 -katlı, taban izolasyonlu binaları 
analiz edilmiştir. Bu çalışma için üstyapının çapraz kütle matrisi $[M]$, sabit tutulan ( $m_{\mathrm{j}}=m$ için $\left.j=1,2, \ldots N\right)$ her katın kütlesi ile karakterize edilir. Her kat için kütle 252.1 ton olarak kabul edilip ve dügüumlerde toplanmıştır. Tüm katların rijitliği sabit olarak dikkate alınır ve $\left(k_{\mathrm{s}}\right)$ parametresi ile ifade edilir. $\left(k_{\mathrm{s}}\right)$ değeri, üstyapının gerekli temel zaman periyodunu ankastre mesnetli $\left(\boldsymbol{T}_{S}\right)$ olarak sağlayacak şekilde seçilir. Kolon ve kiriş boyutları surasıyla $(0.75$ $x 0.75) \mathrm{m}$ ve $(0.5 x 0.5) \mathrm{m}$ olarak kabul edilir. Binaların her türü için $2.4 \times 10^{10} \mathrm{~N} / \mathrm{m}^{2}$ elastikiyet ile M25 beton sınıfı kullanılmıştır. Üstyapının sönümlenmesi açıkça bilinmemektedir. Üst yapıdaki her bir titreşim modunun modal sönümleme oranı varsayılarak, sabit tutulur (yani tüm modlar için \%2).

Bu çalışma için deprem yer hareketleri Los Gatos Tanıtım Merkezi'nde kaydedilen 1989 Loma Prieta depreminin N00E bileşeni, 1994 Northridge depreminin N90S bileşeni, Japonya Meteoroloji Ajansı'nda (JMA) kaydedilen 1995 Kobe depreminin Sylmar ve N00S bileşeni olarak kabul edilmektedir. Loma Prieta, Northridge ve Kobe deprem hareketlerinin maksimum yer ivmesi (PGA) sırasıyla $0.57,0.6$ ve 0.86 g'dır. Şekil 3, kritik sönümlemenin \%2'si için yukarıdaki yer hareketlerinin mesnet yer değiştirme ve ivme spektrumlarını göstermektedir. Analiz, 2 ila 3 saniye arasında izole edilmiş binaya farklı esneklik dikkate alınarak yapılır. Ayrıca, bina dört tip izolasyon sistemleriyle; $\operatorname{LRB}\left(T_{\mathrm{b}}=2,2.5\right.$ ve $\left.3 \mathrm{sn}, \xi_{\mathrm{b}}=0.1\right), \mathrm{NZ}\left(T_{\mathrm{b}}=\right.$ $2,2.5$ ve $3 \mathrm{sn}, \xi_{\mathrm{b}}=0.05, q=2.5 \mathrm{~cm}$, ve $\left(F_{\mathrm{y}} / \boldsymbol{W}=\mathbf{0 . 0 5}\right)$, FPS $\left(T_{\mathrm{b}}=2,2.5\right.$ ve $3 \mathrm{sn}$, $\mu=0.05)$ ve R-FBI $\left(T_{\mathrm{b}}=2,2.5\right.$ ve 3 sn, $\xi_{\mathrm{b}}=0.1$ ve $\left.\mu=0.05\right)$, izole edilmektedir.

Ayrıca, TMD'nin kütle oranı $\% 2, \% 3, \% 5$ ve $\% 10$ olarak alınır. Ayrıca, TMD, binaların her bir katına yerleştirilmiştir. İki saniyelik zaman periyoduna sahip bir izolatör seti için, TMD ve 5, 10 ve 15 katlara ait kütle, rijitlik ve sönümleme gibi parametreler, Tablo 1'de gösterilmektedir.
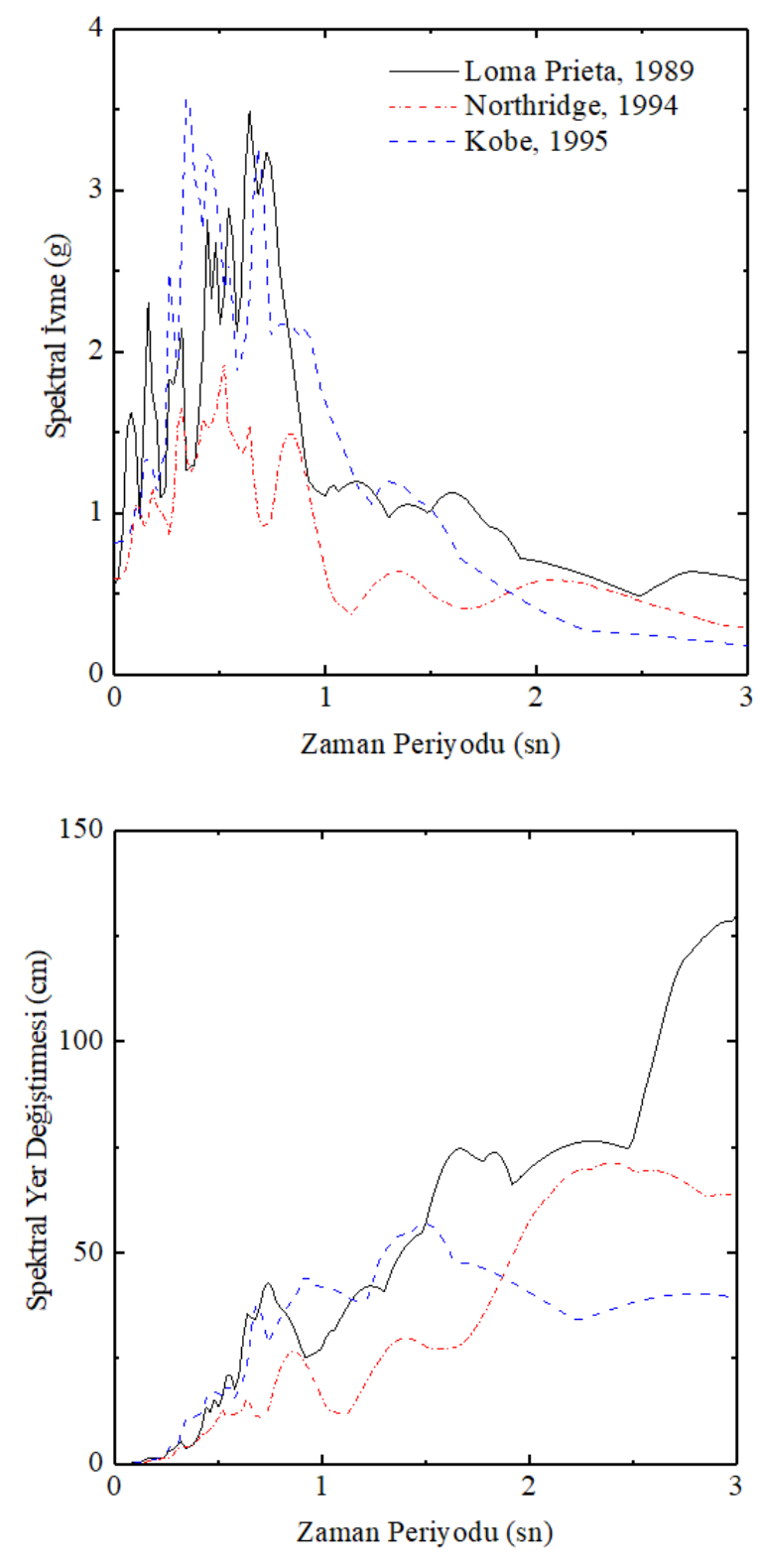

Şekil 3. Loma Prieta 1989, Northridge 1994 ve Kobe 1995 Yer Hareketleri için Tepki Spektrumu 


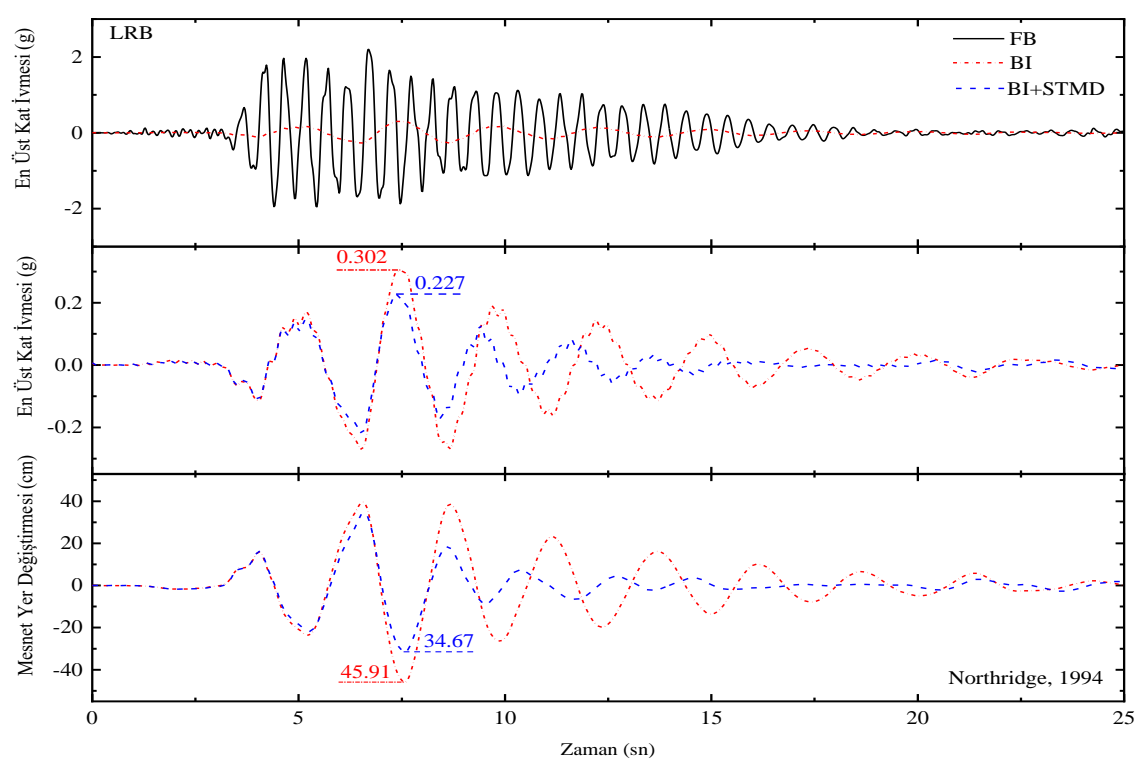

Şekil 4. Northridge 1994 yer hareketi altında ankastre mesnetli (FB), taban izolasyonlu (BI), LRB ( $T_{\mathrm{s}}=0.5 \mathrm{sn}, T_{\mathrm{s}}$ $\left.=2.5 \mathrm{sn}, \xi_{\mathrm{b}}=0.1\right)$ ile izole edilmiş ve en üst katta STMD ile donatılmış 5-katlı taban izolasyonlu binaların en üst kat ivmesi ve mesnet yer değiştirmesi için zaman tanımlı grafikleri.

Tablo 1. İzolatör ve TMD Parametreleri

\begin{tabular}{|c|c|c|c|c|c|}
\hline Kat Sayısı & $\begin{array}{l}\text { Esas Zaman Periyodu } \\
\qquad(\mathrm{sn})\end{array}$ & Cihaz & $\begin{array}{l}\text { Kütle } \\
(\mathrm{kg})\end{array}$ & $\begin{array}{l}\text { Rijitlik } \\
(\mathrm{kN} / \mathrm{m})\end{array}$ & $\begin{array}{l}\text { Sönümleme } \\
\text { (Ns/m) }\end{array}$ \\
\hline & & İzolatör & 126025 & 7455.4 & $c_{\mathrm{b}}=2 \xi_{\mathrm{b}} M \omega_{\mathrm{b}}$ \\
\hline 5 & & $\begin{array}{l}\text { TMD, } \\
\mu=10 \%\end{array}$ & 151230 & 1483.1 & 18943.3 \\
\hline & & İzolatör & 126025 & 13668.1 & $c_{\mathrm{b}}=2 \xi_{\mathrm{b}} M \omega_{\mathrm{b}}$ \\
\hline 10 & 2 & $\begin{array}{l}\text { TMD, } \\
\mu=10 \%\end{array}$ & 277255 & 2706.5 & 34650 \\
\hline & & İzolatör & 126025 & 19880.9 & $c_{\mathrm{b}}=2 \xi_{\mathrm{b}} M \omega_{\mathrm{b}}$ \\
\hline 15 & & $\begin{array}{l}\text { TMD, } \\
\mu=10 \%\end{array}$ & 403280 & 4119.1 & 51554.2 \\
\hline
\end{tabular}




\section{Parametrik Çalışmalar}

Taban izolasyonlu yapıların tepkilerini kontrol etmede TMD'nin performansinı arttırmak için uygun kütle oranı gereklidir. Parametrik çalışmalarda örnek olarak 10katlı yap1 LRB, N-Z, FPS ve R-FBI izolasyon sistemleri ile izole edilmiştir. Tablo 2 farklı deprem yer hareketleri altında 10-katlı taban izolasyonlu yapının tepki azatlımı üzerindeki TMD kütle oranının etkililiği gösterilmiştir. \%2, 3, 5 ve $\% 10^{\prime}$ luk kütle oranlarına sahip TMD en üst katta yerleştirilmiştir, sönümleme oranı ve ayar frekans1 sirasıyla $\% 2$ ve 1 olarak kabul edilmiştir. TMD’nin kütle oranındaki artışla,
TMD'nin taban izolasyonlu yapının en üst kat ivme ve mesnet yer değiştirmesini azaltma üzerindeki etkililiği artmıştır. En üst kat ivmesi $(0.237 \mathrm{~g}$ 'den $0.23 \mathrm{~g}$ 'ye, $0.581 \mathrm{~g}$ 'den $0.570 \mathrm{~g}$ 'ye) ve mesnet yer değiştirmesi (21 cm'den 19 cm'ye ve $81 \mathrm{~cm}$ 'den 65 cm'ye) düşer. Ancak, bazı durumlarda, TMD kütle oranındaki artış, en üst kat ivme oranını etkilemeyebilir veya ivmelenmeyi biraz artırabilir, örneğin, TMD kütle oran $1 \% 5$ 'ten $\% 10$ 'a çıktı ğında, LRB ( ${ }_{\mathrm{b}}=2.5 \mathrm{sec}$ ve $\xi_{\mathrm{b}}=0.1$ ) ile izole edilen 10-katl taban izolasyonlu bir yapıda en üst kat ivmesi $0.289 \mathrm{~g}$ 'dan $0.291 \mathrm{~g}$ 'a yükselir.

Tablo 2. TMD’nin Kütle Oranında Değişimle En Üst Katta TMD ile Donatılmış 10-Katlı Taban-İzolasyonlu Yapının En Üst Kat İvme Varyasyonları

\begin{tabular}{|c|c|c|c|c|c|c|}
\hline \multirow{2}{*}{ ¿ } & \multirow{2}{*}{ 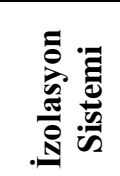 } & \multirow[b]{2}{*}{ F 匟 } & \multicolumn{4}{|c|}{$\begin{array}{l}\text { En Üst Kat İvmesi }(g) \\
\text { TMD Kütle Oranı }(\%)\end{array}$} \\
\hline & & & 2 & 3 & 5 & 10 \\
\hline \multirow{12}{*}{ 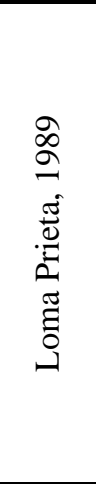 } & \multirow{3}{*}{ LRB } & 2 & 0.517 & 0.529 & 0.539 & 0.508 \\
\hline & & 2.5 & 0.423 & 0.420 & 0.414 & 0.398 \\
\hline & & 3 & 0.415 & 0.399 & 0.369 & 0.319 \\
\hline & \multirow{3}{*}{$\mathrm{N}-\mathrm{Z}$} & 2 & 0.539 & 0.549 & 0.554 & 0.505 \\
\hline & & 2.5 & 0.439 & 0.436 & 0.429 & 0.412 \\
\hline & & 3 & 0.399 & 0.384 & 0.355 & 0.335 \\
\hline & \multirow{3}{*}{ FPS } & 2 & 0.483 & 0.475 & 0.462 & 0.429 \\
\hline & & 2.5 & 0.398 & 0.395 & 0.390 & 0.377 \\
\hline & & 3 & 0.352 & 0.342 & 0.322 & 0.311 \\
\hline & \multirow{3}{*}{ R-FBI } & 2 & 0.510 & 0.510 & 0.502 & 0.459 \\
\hline & & 2.5 & 0.420 & 0.000 & 0.411 & 0.397 \\
\hline & & 3 & 0.359 & 0.349 & 0.340 & 0.330 \\
\hline \multirow{12}{*}{ 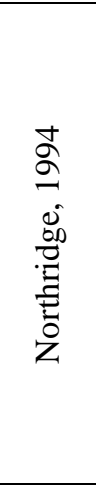 } & \multirow{3}{*}{ LRB } & 2 & 0.406 & 0.394 & 0.372 & 0.325 \\
\hline & & 2.5 & 0.337 & 0.331 & 0.289 & 0.291 \\
\hline & & 3 & 0.290 & 0.286 & 0.277 & 0.258 \\
\hline & \multirow{3}{*}{$\mathrm{N}-\mathrm{Z}$} & 2 & 0.363 & 0.352 & 0.336 & 0.322 \\
\hline & & 2.5 & 0.311 & 0.304 & 0.291 & 0.263 \\
\hline & & 3 & 0.295 & 0.290 & 0.280 & 0.258 \\
\hline & \multirow{4}{*}{ FPS } & 2 & 0.327 & 0.319 & 0.302 & 0.272 \\
\hline & & 2.5 & 0.287 & 0.282 & 0.274 & 0.254 \\
\hline & & 3 & 0.254 & 0.251 & 0.244 & 0.230 \\
\hline & & 2 & 0.337 & 0.329 & 0.316 & 0.304 \\
\hline & \multirow[t]{2}{*}{ R-FBI } & 2.5 & 0.292 & 0.287 & 0.278 & 0.257 \\
\hline & & 3 & 0.274 & 0.270 & 0.263 & 0.247 \\
\hline \multirow{6}{*}{ 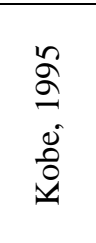 } & \multirow{3}{*}{ LRB } & 2 & 0.508 & 0.509 & 0.511 & 0.514 \\
\hline & & 2.5 & 0.334 & 0.332 & 0.328 & 0.320 \\
\hline & & 3 & 0.251 & 0.250 & 0.249 & 0.245 \\
\hline & \multirow{3}{*}{$\mathrm{N}-\mathrm{Z}$} & 2 & 0.580 & 0.579 & 0.577 & 0.570 \\
\hline & & 2.5 & 0.376 & 0.375 & 0.374 & 0.371 \\
\hline & & 3 & 0.312 & 0.311 & 0.309 & 0.306 \\
\hline
\end{tabular}




\begin{tabular}{cccccc} 
& 2 & 0.466 & 0.466 & 0.466 & 0.467 \\
FPS & 2.5 & 0.297 & 0.296 & 0.292 & 0.288 \\
& 3 & 0.236 & 0.235 & 0.230 & 0.231 \\
& 2 & 0.510 & 0.510 & 0.575 & 0.570 \\
R-FBI & 2.5 & 0.385 & 0.385 & 0.384 & 0.382 \\
& 3 & 0.303 & 0.302 & 0.300 & 0.296 \\
\hline
\end{tabular}

Tablo 3. TMD'nin Kütle Oranında Değişimle En Üst Katta TMD ile Donatılmış 10-Katlı Taban-İzolasyonlu Yapının Mesnet Yer Değiştirme Varyasyonları

\begin{tabular}{|c|c|c|c|c|c|c|}
\hline \multirow{2}{*}{ 离 } & \multirow{2}{*}{ 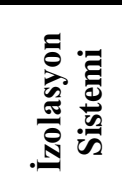 } & \multirow[b]{2}{*}{ 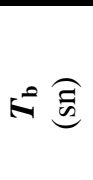 } & \multicolumn{4}{|c|}{$\begin{array}{c}\text { Mesnet Yer Değiştirmesi }(\mathrm{cm}) \\
\text { TMD Kütle Oranı }(\%) \\
\end{array}$} \\
\hline & & & 2 & Tim & 5 & 10 \\
\hline \multirow{12}{*}{ 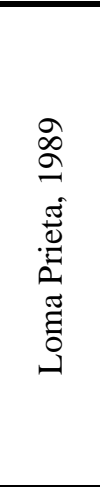 } & \multirow{3}{*}{ LRB } & 2 & 45.30 & 44.18 & 42.00 & 36.92 \\
\hline & & 2.5 & 55.15 & 54.91 & 54.45 & 53.31 \\
\hline & & 3 & 73.92 & 70.79 & 66.76 & 64.53 \\
\hline & \multirow{3}{*}{$\mathrm{N}-\mathrm{Z}$} & 2 & 41.84 & 40.73 & 38.57 & 35.98 \\
\hline & & 2.5 & 52.01 & 51.80 & 51.40 & 50.48 \\
\hline & & 3 & 63.88 & 63.47 & 62.64 & 60.52 \\
\hline & \multirow{4}{*}{ FPS } & 2 & 38.24 & 37.35 & 35.62 & 33.48 \\
\hline & & 2.5 & 49.94 & 49.71 & 49.28 & 48.22 \\
\hline & & 3 & 61.32 & 60.92 & 60.14 & 58.20 \\
\hline & & 2 & 35.50 & 34.61 & 32.87 & 32.63 \\
\hline & \multirow{2}{*}{ R-FBI } & 2.5 & 47.11 & 46.92 & 46.55 & 45.65 \\
\hline & & 3 & 57.73 & 57.36 & 56.61 & 54.75 \\
\hline \multirow{12}{*}{ 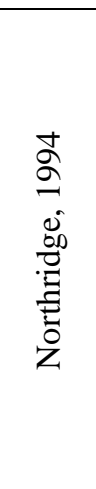 } & \multirow{3}{*}{ LRB } & 2 & 32.46 & 31.67 & 30.23 & 27.14 \\
\hline & & 2.5 & 38.96 & 37.32 & 35.67 & 32.76 \\
\hline & & 3 & 43.37 & 42.88 & 41.25 & 37.53 \\
\hline & \multirow{3}{*}{$\mathrm{N}-\mathrm{Z}$} & 2 & 30.12 & 29.52 & 28.40 & 25.88 \\
\hline & & 2.5 & 34.30 & 33.39 & 32.33 & 30.00 \\
\hline & & 3 & 40.33 & 39.43 & 37.70 & 33.77 \\
\hline & \multirow{4}{*}{ FPS } & 2 & 27.21 & 26.59 & 25.42 & 22.85 \\
\hline & & 2.5 & 32.63 & 32.12 & 31.16 & 28.99 \\
\hline & & 3 & 38.38 & 37.77 & 36.57 & 33.82 \\
\hline & & 2 & 25.35 & 24.85 & 23.87 & 21.65 \\
\hline & \multirow{2}{*}{ R-FBI } & 2.5 & 29.63 & 29.20 & 28.42 & 26.67 \\
\hline & & 3 & 35.55 & 34.89 & 33.63 & 30.75 \\
\hline \multirow{12}{*}{ 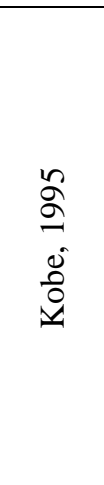 } & \multirow{3}{*}{ LRB } & 2 & 24.10 & 24.00 & 23.79 & 23.12 \\
\hline & & 2.5 & 29.65 & 29.37 & 28.82 & 27.51 \\
\hline & & 3 & 29.63 & 29.28 & 28.59 & 26.99 \\
\hline & \multirow{3}{*}{$\mathrm{N}-\mathrm{Z}$} & 2 & 23.08 & 22.97 & 22.72 & 21.94 \\
\hline & & 2.5 & 28.12 & 27.85 & 27.30 & 25.98 \\
\hline & & 3 & 28.50 & 28.11 & 27.35 & 25.59 \\
\hline & \multirow{3}{*}{ FPS } & 2 & 21.15 & 21.03 & 20.78 & 20.08 \\
\hline & & 2.5 & 26.37 & 26.14 & 25.69 & 24.61 \\
\hline & & 3 & 26.89 & 26.62 & 26.09 & 24.85 \\
\hline & \multirow{3}{*}{ R-FBI } & 2 & 20.50 & 20.28 & 20.00 & 19.22 \\
\hline & & 2.5 & 25.23 & 24.99 & 24.53 & 23.42 \\
\hline & & 3 & 25.99 & 25.70 & 25.12 & 23.77 \\
\hline
\end{tabular}

TMD'ler, taban izolasyonlu yapıların en üst kat ivme ve mesnet yer değiştirmesini azaltmada etkilidir.

Şekil 8 Northridge 1994 yer hareketi altında 10-katlı ankastre mesnetli, taban izolasyonlu ve en üst katta STMD, MTMD'ler ve katlarda d-MTMD'ler ile donatılmış taban izolasyonlu yapının en üst kat ivme ve mesnet yer değiştirmesi için zaman tanımlı grafiklerini göstermektedir. Yap1 LRB $\left(T_{\mathrm{s}}=\right.$ 
$0.5 \mathrm{sn}, \quad T_{\mathrm{b}}=2 \mathrm{sn}$ ve $\xi_{\mathrm{b}}=0.1$ ) ile izole edilmiştir. Tüm TMD şemaları için aynı kütle oranı $(\mu=10 \%)$ düşülmüştür. Grafik, MTMD'ler ve d-MTMD'ler için eşit rijitlik ve sönümleme oranı dikkate alınarak elde edilmiştir. Grafik, izolatörlerin ankastre mesnetli yapının en üst kat ivmesini kontrol etmek için oldukça etkili olduğunu göstermiştir. Grafikte, en üst katta STMD, MTMD'ler ve katlarda d-MTMD'ler ile donatılmış 10-katlı taban izolasyonlu yapının en üst kat ivmesinin önemli ölçüde azaldığ görülmektedir. Ayrica grafik, 10-katlı taban izolasyonlu yapının mesnet yer değiştirmesinin de azaldığını gösteriyor. $\mathrm{Bu}$, izolatörün büyük mesnet yer değiştirmesinin TMD'leri monte ederek azaltıldığını ve aynı zamanda taban izolasyonlu yapının en üst kat ivmesini azaltmak için oldukça etkili olduğunu doğrulamaktadır. MTMD'lerin ve d-MTMD'lerin kurulması, STMD'ye kıyasla en üst kat ivme ve mesnet yer değiştirmesinin azaltılmasında önemli ölçüde faydalıdır. Ancak, d-MTMD'ler, büyük kütlelerin farklı kat seviyelerinde bölünmesi ve dağıtılması nedeniyle MTMD'lere kiyasla daha yararlıdır. En üst kat ivme ve mesnet yer değiştirmesindeki benzer azalma Şekil 6, 7 ve 8'de gösterildiği gibi sırasıyla (i) $\mathrm{NZ}\left(T_{\mathrm{s}}=\right.$ $0.5 \mathrm{sn}, T_{\mathrm{b}}=2 \mathrm{sn}, \quad \xi_{\mathrm{b}}=0.05, q=2.5 \mathrm{~cm}$ ve $\left.F_{\mathrm{y}} / W=0.05\right)$, (ii) FPS $\left(T_{\mathrm{s}}=0.5 \mathrm{sn}, T_{\mathrm{b}}=\right.$ 2sn, ve $\mu=0.05)$; (iii) R-FBI $\left(T_{\mathrm{b}}=2 \mathrm{sn}\right.$, $\xi_{\mathrm{b}}=0.1$ ve $\mu=0.05$ ) ile izole edilmiş ve en üst katta STMD, MTMD'ler ve katlarda dMTMD'ler ile donatılmış 10-katlı taban izolasyonlu yapının durumunda gözlenmiştir.

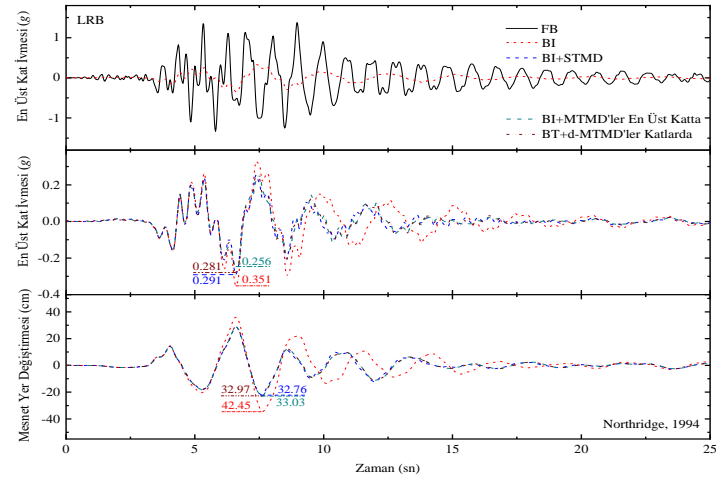

Şekil 5. Northridge 1994 yer hareketi altında 10-katlı ankastre mesnetli, taban izolasyonlu, LRB $\left(\mathrm{T}_{\mathrm{s}}=0.5 \mathrm{sn}\right.$, $\mathrm{T}_{\mathrm{b}}=2 \mathrm{sn}$ ve $\left.\xi_{\mathrm{b}}=0.1\right)$ ile izole edilmiş ve en üst katta STMD, MTMD'ler ve katlarda d-MTMD'ler ile donatılmış taban izolasyonlu yapının en üst kat ivme ve mesnet yer değiştirmesi için zaman tanımlı grafikleri.

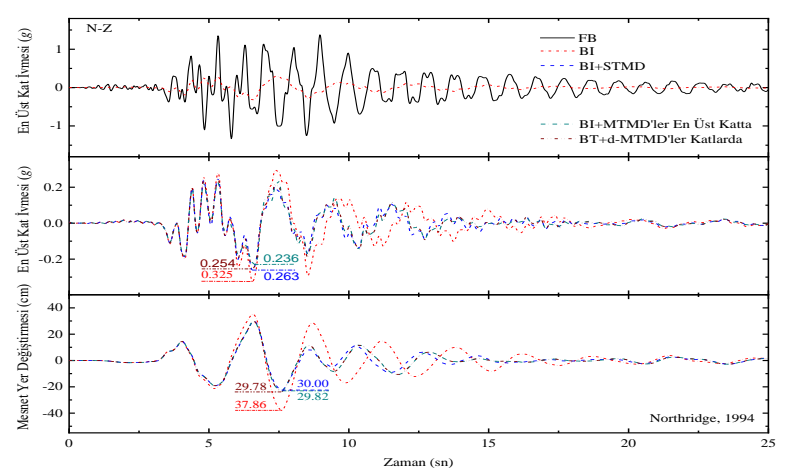

Şekil 6. Northridge 1994 yer hareketi altında 10-katlı ankastre mesnetli, taban izolasyonlu, N-Z $\left(T_{\mathrm{b}}=2.5 \mathrm{sn}\right.$, $\xi_{\mathrm{b}}=0.05, q=2.5 \mathrm{~cm}, \quad$ ve $\left.F_{\mathrm{y}} / W=0.05\right) \quad$ ile izole edilmiş ve en üst katta STMD, MTMD’ler ve katlarda d-MTMD'ler ile donatılmış taban izolasyonlu yapının en üst kat ivme ve mesnet yer değiştirmesi için zaman tanımlı grafikleri. 


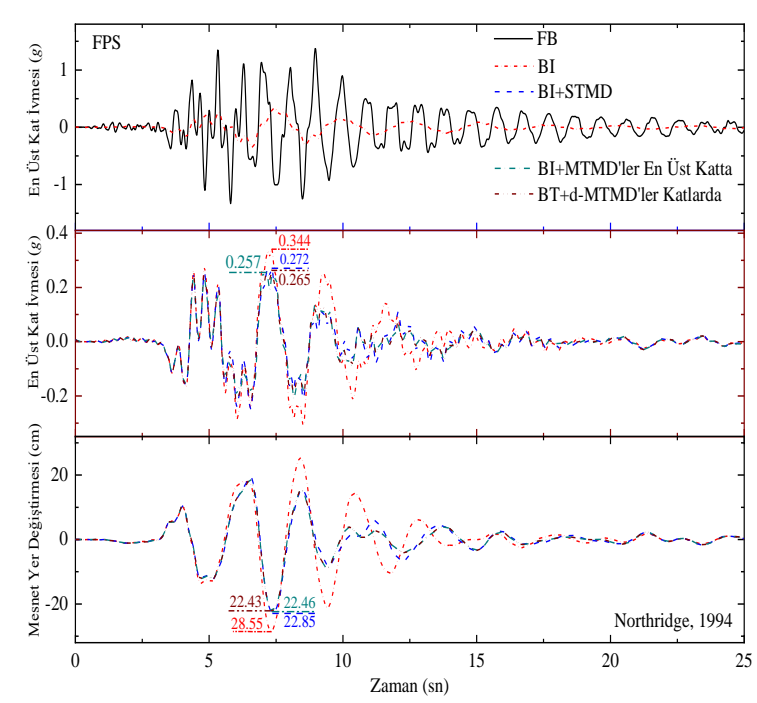

Şekil 7. Northridge 1994 yer hareketi altında 10-katlı ankastre mesnetli, taban izolasyonlu, FPS $\left(T_{\mathrm{b}}=2 s n\right.$ ve $\mu=0.05$ ) ile izole edilmiş ve en üst katta STMD, MTMD'ler ve katlarda d-MTMD'ler ile donatılmış taban izolasyonlu yapının en üst kat ivme ve mesnet yer değiştirmesi için zaman tanımlı grafikleri.

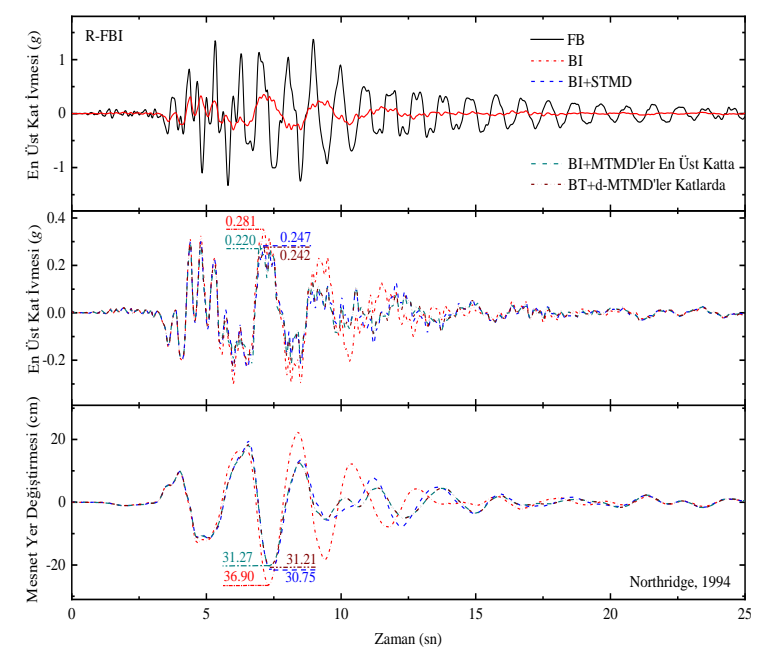

Şekil 8. Northridge 1994 yer hareketi altında 10-katlı ankastre mesnetli, taban izolasyonlu, R-FBI $\left(T_{\mathrm{b}}=3 s n\right.$ $\xi_{\mathrm{b}}=0.1$ ve $\mu=0.05$ ) ile izole edilmiş ve en üst katta STMD, MTMD'ler ve katlarda d-MTMD'ler ile donatılmış taban izolasyonlu yapının en üst kat ivme ve mesnet yer değiştirmesi için zaman tanımlı grafikleri.

\section{Sonuç}

Taban izolasyonlu yapının zaman periyodundaki artışla üst kat ivmesi azalmakta, ancak mesnet yer değiştirmesi artmaktadır. TMD'nin etkililiği, eşit kütle oranına sahip bir karma sistemde izolatörlerin zaman periyodundaki artışı ile azalmaktadır. TMD'nin taban izolasyonlu yapılarda kurulması, hem üst kattaki ivmeyi hem de mesnetteki yer değiştirmeyi kontrol etmede oldukça etkili olmaktadır. Ayrıca, TMD'nin etkililiği, taban izolasyonlu yapıların en üst kat ivme ve mesnet yer değiştirmesinin kontrol edilmesinde kütle oranlarının artırılmasıyla geliştirilmektedir. Taban izolasyonlu yapıların en üst katlarına TMD yerleştirmek, alt katlara yerleştirme ile karşılaştırıldığında maksimum tepki indirgemesi sağlanmaktadır.

Taban izolasyonlu yapılarda MTMD'lerin ve d-MTMD'lerin kurulması, STMD'nin kurulmasına kıyasla en üst kat ivme azaltılmasında önemli ölçüde faydalı olduğu görülmektedir. Taban izolasyonlu yapıların en üst katlarında STMD, MTMD'lerin ve katlarında d-MTMD'lerin kurulmasından mesnet yer değiştirmede neredeyse eşit bir azalma elde edilebilmektedir. d-MTMD'ler, büyük kütlelerin farklı kat seviyelerinde bölünmesi ve dağıtılması nedeniyle STMD ve MTMD'lere kıyasla daha faydalı olmaktadır. Eşit olmayan sönümleme katsayısına sahip her iki MTMD seti ((i) eşit rijitlik ve eşit sönümleme oranına sahip TMD’ler, (ii) eşit kütleye ve eşit sönümleme oranına sahip TMD’ler)) de tüm durumlarda benzer tepki azaltımı sağlamaktadır. 


\section{Kaynaklar}

Brock, J. E. 1946. A Note on the Damped Vibration Absorber, Journal of Applied Mechanics, 68: A-284.

Frahm, H. 1909. Device for Damping Vibration of Bodies, US Patent No: 989958.

Iwanami, K., Seto, K. 1984. Optimum Design of Dual Tuned Mass Dampers and Their Effectiveness, Japan Society of Mechanical Engineering, 50(1): 4452.

Jangid, R.S. 1995. Dynamic Characteristics of Structures with Multiple Tuned Mass Dampers, Structural Engineering and Mechanics, 3(5): 497-509.

Jangid, R.S., Datta, T.K. 1995. Performance of Base Isolation Systems for Asymmetric Building Subject to Random Excitation, Engineering Structures, 17 (6): 443-454.

Kareem, A. 1997. Modelling of BaseIsolated Buildings with Passive Dampers Under Winds, Journal of Wind Engineering and Industrial Aerodynamics, 72(1-3): 323-333.

Kareem, A., Kline, S. 1995. Performance of Multiple Mass Dampers Under Random Loading, Journal of Structural Engineering, 121(2): 348-341.

Kelly, J.M. 1986. Aseismic Base-isolation: Review and Bibliography, Soil Dynamics and Earthquake Engineering, 5(4): 202-216.

Krishnamoorthy, A., Shetty, K.K. 2005. Seismic Response Control of Structure Using Tuned Mass Damper, Journal of the Institution of Engineers (India): Civil Engineering Division, 86 (AUG): 58-61.
Li, C., Liu, Y. 2002. Further Characteristics for Multiple Tuned Mass Dampers, Journal of Structural Engineering, 128 (10): 1362-1365.

Mokha, A., Constantinou, M., Reinhorn, A. 1990. Teflon Bearings in BaseIsolation, Journal of Structural Engineering, 116(2): 438-454.

Palazzo, B., Petti, L. 1997. Combined Control Strategy: Base Isolation and Tuned Mass Damping, Journal of Earthquake Technology, 36(2-4): 121137.

Palazzo, B., Petti, L. ,M. Ligio, D. 1999. Response of Base Isolated Systems Equipped with Tuned Mass Dampers to Random Excitations, Journal of Structural Control, 4(11): 9-22.

Rana, R. ,Soong, T.T. 1998. Parametric Study and Simplified Design of Tuned Mass Dampers, Engineering Structures, 20(3): 193-204.

Randall, S.E., Halsted, D.M. ,Taylor, D.L. 1981. Optimum Vibration Absorbers for Linear Damped Systems, Mechanical Design, 103(12): 908-913.

Soong, T.T. ,Dargush G.F. 1997. Passive Energy Dissipation Systems in Structural Engineering, John Wily and Sons Yayınları, 368s. Chichester.

Su, L., Ahmadi, G., Tadjbakhsh, I.G. 1990. A Probabilistic Comparative Study of Base Isolation Systems, Mechanics of Structures and Machines, 18(1): 107133.

Tsai, H. 1995. The Effect of Tuned-Mass Dampers on the Seismic Response of Base-Isolated Structures, International Journal of Solid Structures, 32(8/9): 1199-1210.

Xu, K., Igusa, T. 1992. Dynamic Characteristics of Multiple 
Substructure with Closely Spaced Frequencies, Earthquake Engineering and Structural Dynamics, 21(12): 1059-1070.

Yamaguchi, H., Harnpornchai, N. 1993.

Fundamental Characteristics of Multiple Tuned Mass Dampers for Suppressing Harmonically Forced Oscillations, Earthquake Engineering and Structural Dynamics, 22(1): 51-62.

Yang, J., Dandelions, A., Liu, S. 1991. Aseismic Hybrid Control Systems for Building Structures, Journal of Engineering Mechanics, 117(4): 836853.

Naimi, S., Kamiarfar, M. 2016. Faya Yakın Depremlerin Etkisi ve Yapıların Güçlendirme Amaci ile İncelenmesi, İstanbul Aydın Üniversitesi Dergisi, 32: 127-136.

Bekdaş, G. ve Niğdeli, S. M. (2011), "Estimating Optimum Parameters of Tuned Mass Dampers using Harmony Search", Engineering Structures, 33(9), Sayfa 2716-2723.

Bekdaş, G., ve Niğdeli, S. M. (2013), "Mass ratio factor for optimum tuned mass damper strategies", International Journal of Mechanical Sciences, 71, Sayfa 68-84.

Özkaya, C., Akyüz, A., Caner, A., Dicleli, M. ve Pınarbaşı, S. (2011), "Development of a New Rubber Seismic Isolator: 'Ball Rubber Bearing”, Earthquake Engineering and Structural Dynamics, 40(12), Sayfa1337-1352. 